\section{Biliocutaneous Fistula Following Biliary Stent Migration}

A 58-year-old man with a clinical picture of pancreatitis and cholangitis was admitted at our endoscopic unit 12 hours after a failed endoscopic sphincterotomy.

Endoscopic retrograde cholangiopancreatography showed the presence of multiple erosions on the duodenal wall and an incomplete papillotomy; the cholangiogram revealed a stricture of the retropancreatic bile duct with dilatation of the proximal tract; visualization of the pancreatic duct was not attempted. A $10-\mathrm{Fr}$, $12-\mathrm{cm}$ straight biliary stent was inserted to decompress the bile duct and relieve cholangitis. At 10 days after returning to the referring hospital, the patient underwent open cholecystectomy and drainage of peripancreatic fluid collection. The biliary stent was left in situ, and subhepatic and retroperitoneal drains were positioned.

At 1 month after being discharged from the hospital, the patient developed right iliac fossa pain, fever $\left(37.5-37.8^{\circ} \mathrm{C}\right)$, and marked erythema at the removal site of the retroperitoneal drainage, followed by the appearance of a fistulous orifice producing biliary discharge.

A fistulogram showed the extravasation of contrast into the drain sites and the stent located partially in the retroperitoneal space, in the duodenum, and in the bile duct (Figure 1).

Duodenoscopy showed that the stent came out from the papilla and was inserted into the posterior wall of the duodenum; the stent was grasped with a rat-toothed forceps and withdrawn: the fistula closed spontaneously during the next 48 hours.

The migration of biliary endoprostheses has an overall incidence of 3-6\% (proximal $4.9 \%$ and distal 5.9\%) [1-4]. Distal migration can result in massive hemorrhage or peritonitis; sometimes the patient may remain minimally symptomatic if the perforation is contained in the retroperitoneal space.

In our patient the retroduodenal perforation followed by distal migration was most probably the result of weakness of the duodenal wall induced by multiple erosions and surgical manipulation during drainage of the peripancreatic fluid collection.

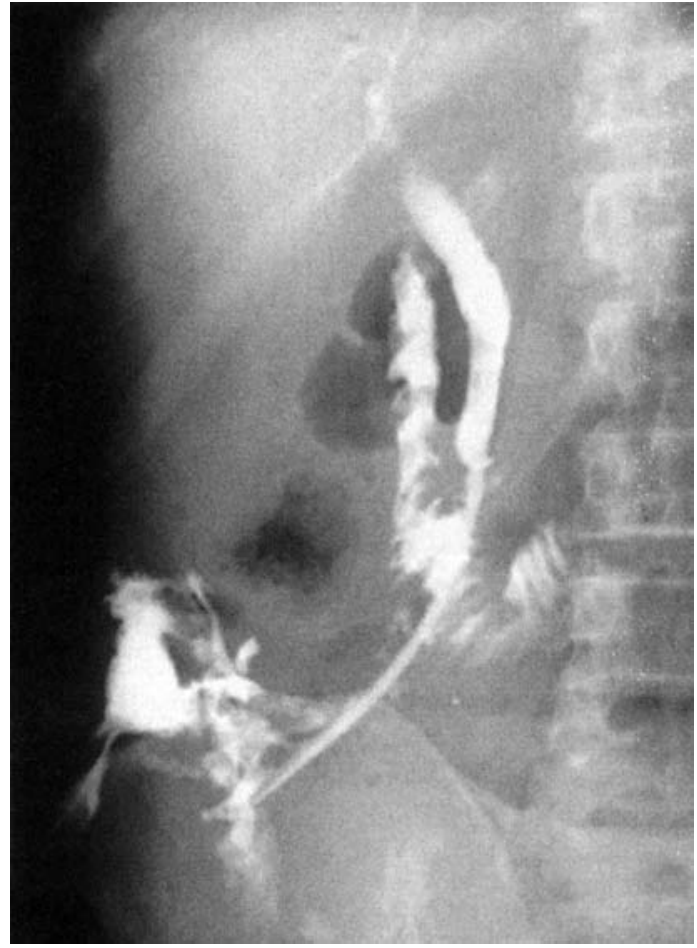

Figure 1 A fistulogram demonstrating the extravasation of contrast into the drains site and the stent located partially in the common bile duct, in the duodenum, and in the retroperitoneal space

It is difficult to give advice on how to avoid distal stent migration; the use of pigtail stents or shorter stents $(7 \mathrm{~cm})$, when combined with minimal length of endoscopic sphinterotomy, may reduce the incidence of this complication.

\section{Distefano, G. Bonanno, A. Russo}

Cattedra di Chirurgia Endoscopica,

Dipartimento di Chirurgia,

Policlinico dell'Università, Catania, Italy

\section{References}

${ }^{1}$ Johanson JF, Schmalz MJ, Geenen JE, et al. Incidence and risk factors for biliary and pancreatic stent migration. Gastrointest Endosc 1992; 38: 341-346

${ }^{2}$ Humar A, Barron PT, Sekar ASC, et al. Pancreatitis and duodenal perforation as complications of an endoscopically placed biliary stent. Gastrointest Endosc 1994; 40: 365-366

${ }^{3}$ Deviere J, Baize M, De Toeuf J, et al. Long-term follow-up of patients with hilar malignant stricture treated by endoscopic internal biliary drainage. Gastrointest Endosc 1988; 34: 95-101

${ }^{4}$ Walta DC, Fausel CS, Brant B. Endoscopic biliary stents and obstructive jaundice. Am J Surg 1987; 153: 444-447

Corresponding Author

A. Russo, M.D.

Policlinico Università

Via S. Sofia, 84

95125 Catania

Italy

Fax: +39-095-337065

E-mail: arusso@mbox.unict.it 